\title{
Posibilidades de la reconstrucción tridimensional de zonas patrimoniales en base a fotogrametría y escáner LIDAR. El Barranco de la ciudad de Cuenca como caso de estudio
}

\author{
Oscar Montero $^{1}$, Juan Sardi ${ }^{1}$, M. Augusta Hermida ${ }^{2}$ (it \\ ${ }^{1}$ Facultad de Arquitectura y Urbanismo, Universidad de Cuenca, Cuenca, Ecuador \\ ${ }^{2}$ Departamento de Espacio y Población, LlactaLAB - Ciudades Sustentables, Facultad de \\ Arquitectura y Urbanismo, Universidad de Cuenca, Cuenca, Ecuador. \\ Autor para correspondencia: augusta.hermida@ucuenca.edu.ec \\ Fecha de recepción: 22 de octubre 2017 - Fecha de acepción: 14 de diciembre 2017
}

\begin{abstract}
RESUMEN
La emergente necesidad de información actualizada, junto a la falta de documentación adecuada de sectores históricos de ciudad, además del desarrollo tecnológico acelerado de la época, ha provocado la creación de diversas herramientas para el levantamiento de información geográfica, topográfica, y arqueológica, que pueden contribuir al estudio de las transformaciones urbano-morfológicas y a la documentación y protección del patrimonio edificado. Con estos antecedentes, este estudio pretende validar una metodología para la identificación y análisis de alteraciones arquitectónicas como urbanas, en el campo del patrimonio edificado. Para esto, se llevó a cabo un levantamiento detallado mediante fotogrametría aérea y terrestre, en base al uso de herramientas que generan datos bidimensionales como son el Drone DJI Phantom 4, Cámara Nikon D5300, Cámara GoPro Hero 3 Black Edition y un Smartphone Iphone 7. De igual forma, este estudio se complementó con un levantamiento tridimensional mediante escáner láser LIDAR. Los datos se obtuvieron en base a vuelos ortogonales con dron, los cuales se complementaron, mediante documentación parcial de fachadas de las edificaciones del El Barranco de Cuenca en Ecuador, con las otras herramientas bidimensionales y tridimensionales antes descritas. Este proceso se llevó a cabo en dos ocasiones, con un lapso de 4 meses entre sí, con el fin de identificar posibles cambios. Al completar el procesamiento de los datos, se encontraron dos casos en donde las edificaciones fueron alteradas en diferente magnitud. Además, se estableció la versatilidad de los instrumentos utilizados para la reconstrucción tridimensional de nubes de puntos en nuestro medio. En este sentido, el escáner láser LIDAR fue la herramienta que brindó mejores resultados, sin embargo, el levantamiento tomó más tiempo y fue más costoso; por otro lado, considerando la relación calidad-precio, el drone DJI Phantom 4 resultó ser el artefacto más recomendable para este tipo de estudios.
\end{abstract}

Palabras clave: Fotogrametría digital, reconstrucción tridimensional, patrimonio edificado, transformaciones urbano-morfológicas, nubes de puntos.

\begin{abstract}
The emerging need for up-to-date information, coupled with the lack of adequate documentation of historical city sectors, as well as the accelerated technological development of the time, has led to the creation of several tools for surveying geographic, topographic and archaeological information that may contribute to the study of urban-morphological transformations and to the documentation and protection of built heritage. With this background, the study aimed to validate a methodology for the identification and analysis of built heritage alterations. A detailed survey was carried out using aerial and terrestrial photogrammetry, based on the use of tools that generate two-dimensional data such as Drone DJI Phantom 4, Nikon D5300 camera, GoPro Hero 3 Black Edition camera, and an Iphone 7 Smartphone. In the same way, this study was complemented with a three-dimensional method, based on a LIDAR laser scanner. The data was obtained based on orthogonal drone flights, which were complemented by
\end{abstract}


partial documentation of facades of some of the buildings in El Barranco de Cuenca, Ecuador, obtained through the before mentioned two and three-dimensional tools. This process was carried out twice, with an interval of 4 months, to identify changes. When completing the data processing, two cases were found where the buildings were altered in different magnitude. In addition, the research served to establish the most versatile instruments for the three-dimensional reconstruction of point clouds in the historical city of Cuenca. In this sense, the LIDAR technique is the tool that provided the best results, however, the survey took more time and was more expensive; on the other hand, considering the qualityprice ratio, the DJI Phantom 4 drone turned out to be the most recommended device for this type of studies.

Keywords: Digital photogrammetry, three-dimensional reconstruction, built heritage, urbanmorphological transformations, points clouds.

\section{INTRODUCCIÓN}

\subsection{Antecedentes}

Las ciudades se constituyen como organismos vivos, que tienen su propio metabolismo y que están en constante interacción con un sinnúmero de factores, que las hacen susceptibles a cambios o transformaciones en diversas escalas (Perera, 2015). En este contexto es fundamental entender las dos escalas que las definen: la primera, más conocida como forma urbana, que es la forma física de una ciudad, organizada por la arquitectura pública y distribuida a lo largo del territorio, dando coherencia como conjunto y haciéndola reconocible (Samper, 2003); y la morfología urbana que se enfoca en el contexto construido de un sector específico (Doherty, Nakanishi, Bai, \& Meyers, 2009). Por su parte, se entiende por patrimonio cultural al "...conjunto de bienes muebles, inmuebles e inmateriales que hemos heredado del pasado y que hemos decidido que merece la pena proteger como parte de nuestras señas de identidad social e histórica” (Querol, 2010). La función de los bienes patrimoniales es múltiple porque permite generar espacios de recorrido turístico y plazas de empleo, fomentar el sentido de apropiación de los espacios históricos en las personas, mejorar la comunicación cultural, entre otros. Debido a todos los beneficios que se pueden lograr con una correcta restauración, conservación y mantenimiento de los bienes patrimoniales, múltiples organizaciones han determinado acciones adecuadas para el trato de los bienes inmuebles que tienen valor patrimonial. Es así como la construcción de modelos tridimensionales a través de imágenes y el desarrollo de simulaciones dinámicas, son las técnicas más útiles para la generación de modelos arquitectónicos hiperrealistas, así como para la planificación de intervenciones urbanas en ciudades históricas (Bacigalupo \& Cessari, 2013). La fotogrametría digital, permite convertir una serie de fotografías bidimensionales capturadas desde distintos ángulos, en modelos tridimensionales precisos que aportan a los métodos de documentación dimensional (Vidanovski, 2016).

En la arquitectura, históricamente se han utilizado modelos o maquetas físicas para tratar de representar la complejidad tridimensional que poseen los distintos tipos de proyectos planteados. $\mathrm{Al}$ tratarse de grandes extensiones de territorio, es necesario otro tipo de representación, generalmente usada para el ordenamiento territorial y la arquitectura paisajística, entre estas está la elaboración de mapas, planos y ortofotografías, en donde se abstrae la realidad y se la presenta en una condición bidimensional. Sin embargo, en la actualidad surge la necesidad de realizar un cambio en el modelo tradicional de investigación bidimensional, a uno tridimensional aprovechando la disponibilidad de nuevas tecnologías aptas para la captura de datos, como lo son las nubes de puntos.

Existen casos de estudio en donde la adaptabilidad que presentan algunas técnicas de reconstrucción tridimensional no se ve afectada por el contexto que la rodea, por ejemplo, en el caso de una ciudad mediterránea fortificada en el Golfo de Castellammare (Italia), se llevó a cabo un análisis de técnicas de estudio y realidad virtual para producir, navegar y explorar los entornos construidos que poseen valor cultural. De esta manera, se conjugaron datos multidisciplinarios que se utilizaron para la generación de polígonos mediante un software CAD de dibujo y posteriormente la aplicación de imágenes rectificadas por fotogrametría representadas como texturas en cada modelo (Bacigalupo \& Cesari, 2003). 
También destacan varios softwares enfocados en la generación y manejo de nubes de puntos para afrontar elementos o hitos históricos de menor escala. En el caso de la Fuente de la Calle Los Cristos, Málaga, España, se utilizó el programa Agisoft PhotoScan, en donde el resultado fue una malla tridimensional conformada por miles de polígonos, que representan de manera fiable la volumetría y su textura real (hiperrealista) (Cámara \& Latorre, 2003).

Ante la presencia de objetos de mayor magnitud, varios estudios han optado por subdividir la etapa de levantamiento en base a criterios mensurables o de clasificación de elementos constructivos, con el fin de agilitar y organizar los procesos de reconstrucciones de cada nube de puntos parcial, para luego generar un modelo tridimensional unificado. Tanto la Catedral de Santa María de Vitorio como el Palacio de Magdalena en Santander, España, corresponden a estas metodologías respectivamente. El post-proceso de las nubes de puntos se enfocó en el enlace de las mismas (Cámara \& Latorre, 2003).

La calidad de representación de los detalles más ínfimos permite una visualización de las escenas con mayores estándares de resolución. Es así como, para el caso del Convento de Pomposa, Ferrera, Italia, fue necesario enfatizar el levantamiento de elementos como arcos, carpintería de ventanas, capiteles, aleros, entre otros componentes específicos, para complementar la reconstrucción general con estos tipos de modelos individuales (El-Hakim, Whiting, Gonzo, \& Girardi, 2005).

Además de la reconstrucción tridimensional de edificaciones puntuales, esta metodología se ha aplicado también en estudios de sectores de una ciudad. En Jakarta (Indonesia), se analizaron y determinaron las posibles soluciones a los diferentes escenarios de inundación a lo largo de río Cilliwung basándose en la utilización de nubes de puntos para la generación de simulaciones hidrodinámicas y de modelos de rendimiento cuantitativos para determinar su efectividad. En la primera fase se adquirieron y procesaron los datos obtenidos mediante nubes de puntos tridimensionales; en la segunda, se analizaron las herramientas y diferentes flujos de trabajo que permitan la completa manejabilidad de los modelos generados; luego se definieron los posibles escenarios óptimos y tendenciales; y para finalizar, se incorporó a los modelos, gráficos o visuales, la cualidad métrica o cuantitativa (Ervine, 2016). Este caso fue uno de los más representativos, debido a su similitud con el lugar de estudio.

\subsection{Sector de estudio}

La investigación tuvo como escenario el sector denominado El Barranco, emplazado en el límite sur de la segunda terraza fluvial de la ciudad de Cuenca, ubicada en la región andina del sur del Ecuador. Se constituye como una barrera que separa el casco histórico de la ciudad contemporánea. El territorio en cuestión ha sido cuna de varias culturas importantes: los Cañaris, los Incas y los españoles. Cuenca fue construida con una plaza central o plaza mayor y una traza en damero que se extiende hasta el límite sur de la ciudad colonial: el río Tomebamba. Esta frontera natural se conoce como El Barranco, y constituye el único hito que separa la ciudad antigua de la zona de El Ejido (Borrero Vega, 2006).

\subsection{Objetivos del trabajo}

Con esta investigación se pretende: validar una metodología de análisis de transformaciones urbanomorfológicas de un sector histórico de ciudad, mediante la construcción de un modelo tridimensional íntegro de la primera línea edificada del río Tomebamba, desde el Puente del Centenario hasta el Puente de Todos Santos; el análisis comparativo y secuencial de las transformaciones suscitadas en el área de estudio en un lapso de 4 meses; y, la determinación de las ventajas y desventajas de la metodología aplicada a la gestión y control del patrimonio edificado.

\section{METODOLOGÍA}

Conocer y entender cómo trabaja la fotogrametría es imprescindible para poder aplicar la metodología utilizada en este proyecto de investigación. La Sociedad Internacional de Fotogrametría y Sensores Remotos, ISPRS, define a la fotogrametría como "la ciencia de realizar mediciones e interpretaciones 
confiables por medio de las fotografías, para de esa manera obtener características métricas y geométricas (dimensión, forma y posición) del objeto fotografiado” (Jáuregui, 2001). Según este autor y Guerrero, Pajares, \& Guijarro (2011) la fotogrametría digital fundamentalmente aplica los principios de la visión estereoscópica para realizar la reconstrucción de los modelos tridimensionales. Es decir, este tipo de visión natural del ser humano consiste en la obtención de imágenes de un mismo objeto desde dos posiciones ligeramente diferentes (la posición de cada ojo), las cuales son transmitidas hacia el cerebro; luego mediante un proceso de comparación y triangulación de las imágenes capturadas, se logra interpretar las diferencias de profundidad de los objetos.

Según Remondino, Barazzetti, Next, Scaioni, \& Sarazzi (2011) “... en la actualidad la reconstrucción de modelos tridimensionales del patrimonio arquitectónico demanda metodologías que sean capaces de capturar y generar un modelo digital vasto en detalles geométricos que faciliten y mejoren la percepción del inmueble”, por lo que la fotogrametría desde Vehículos Aéreos No Tripulados, UAV's ${ }^{1}$ por sus siglas en inglés, se convierte en una herramienta pertinente. Los UAV se definen como aeronaves autónomas que son conducidas de manera remota. Los primeros usos a los que se sometieron hace aproximadamente tres décadas, fueron militares para luego empezar a tener usos civiles como el mapeo de zonas en dos y tres dimensiones.

Para la etapa de levantamiento ortogonal se utilizó como UAV, el cuadricóptero Dji Phantom 4, fabricado por la empresa DJI. La aeronave presenta una velocidad máxima de $15 \mathrm{~m} / \mathrm{s}$, con una fuerte señal de cobertura de aproximadamente dos kilómetros, además de un promedio de vuelo de 28 minutos. La cámara incorporada en el dispositivo de vuelo mantiene altos niveles de calidad en cuanto a resolución se refiere. Es importante mencionar que el amplio campo de visión, de $94^{\circ}$, genera fotografías de grandes dimensiones, sumado a un correcto balance de colores y nitidez.

Con estos antecedentes la metodología empleada para este proyecto de investigación puede ser resumida en cuatro fases: 1) reconocimiento del área de estudio, 2) levantamiento y captura de información, 3) procesamiento de datos y visualización de modelo tridimensional unificado, e 4) identificación de transformaciones urbano-morfológicas.

\subsection{Reconocimiento del sector de estudio}

Para llevar a cabo un correcto proceso de levantamiento, es imprescindible identificar los diversos obstáculos, información relevante al momento de establecer la altura de vuelos de la aeronave. Estos obstáculos pueden ser aéreos o terrestres: ramas de árboles, edificaciones de gran altura, antenas repetidoras de señal, entre otros. El sector de estudio se caracteriza por presentar una topografía irregular marcada por un desnivel de aproximadamente 45 metros. Se suma a esto la abundante vegetación, la cual determinó la altura mínima a la que el UAV debía realizar el levantamiento ortogonal: 85 metros. Es importante mencionar que, previo a la realización de vuelos con cualquier tipo de UAV, es necesario tener en cuenta las posibles restricciones legislativas estipuladas por la Dirección de Aviación Civil (DAC) que incluye horarios de tráfico aéreo, seguros contra accidentes, sitios restringidos, entre otras.

\subsection{Levantamiento y captura de información}

Esta fase de la investigación es la que demanda mayor rigor y tiempo de ejecución. Se dividió en dos partes: la captura de información mediante vuelo ortogonal y los levantamientos parciales de cada edificación.

Para el levantamiento ortogonal, fue necesario realizar una planificación de vuelo con la ayuda de la aplicación para Smartphone Maps Made Easy, la cual permite delimitar la superficie a fotografiar y las diferentes configuraciones o parámetros necesarios como altura y velocidad de vuelo, tiempo máximo de trabajo, superficie de traslape, entre otras. En primera instancia, se trazó un perímetro de 14.42 ha, para luego dibujar las diferentes líneas de trayectoria que seguiría el dron. Es importante mencionar que la altura de vuelo a la que se realiza el trabajo afectará en la cantidad y separación de cada una de las directrices de vuelo. El levantamiento se configuró con una velocidad de vuelo de 8.5 $\mathrm{m} \mathrm{s}^{-1}$, altura de vuelo de 75 metros y un tiempo de trabajo máximo de 20 minutos, de lo cual se obtuvo

1 UAV: Unmanned Aerial Vehicle 
un total de 310 fotografías que sirvieron para los procesos posteriores. Todas las etapas del vuelo despegue, levantamiento y aterrizaje- se efectuaron de manera asistida.

Con el fin de complementar la información generada con el vuelo ortogonal, se realizaron documentaciones parciales de cada una de las edificaciones que se encuentran en la primera línea edificada del sector de estudio, para lo cual se utilizaron diferentes herramientas de captura de información. Entre estas herramientas se usó un UAV (Drone DJI Phantom 4), una cámara semiprofesional (Nikon D5300), una cámara con lente gran angular (GoPro Hero Black Edition), un smartphone (Iphone 7), todas estas herramientas se seleccionaron en función de su asequibilidad. La información recopilada por estas 4 herramientas brinda datos bidimensionales en forma de fotografías, que deben ser procesadas para poder obtener un modelo tridimensional expresado en nubes de puntos. Éstos, al capturar y arrojar un mismo tipo de información, son susceptibles a combinaciones que potencialicen los resultados. Además de éstas, se implementó una quinta herramienta, consistente en un escáner láser (LIDAR FARO x130). Éste posee la capacidad de generar un modelo tridimensional sin necesidad de un proceso fotogramétrico.

La información recopilada por estas cinco herramientas sirvió para efectuar la reconstrucción tridimensional del sector de estudio. Asimismo, se compararon las herramientas, con el fin de determinar su efectividad y rendimiento.

El proceso seguido se basó tanto en los distintos tipos de implantación de las edificaciones, como en las estrategias necesarias para la captura de fotografías para cada caso. En el caso de las edificaciones continuas sin retiro frontal, la estrategia adecuada fue la captura de imágenes paralelas a las edificaciones, procurando mantener un traslape de $50 \%$ entre ellas (Fig. 1); en las edificaciones continuas con retiro frontal, se procedió a ingresar al predio para realizar tomas con mayor detalle; en el caso de las edificaciones esquineras fue necesario trazar una circunferencia ficticia alrededor de cada predio, manteniendo un desplazamiento de 5 a $10^{\circ}$ entre la ubicación de cada cámara.

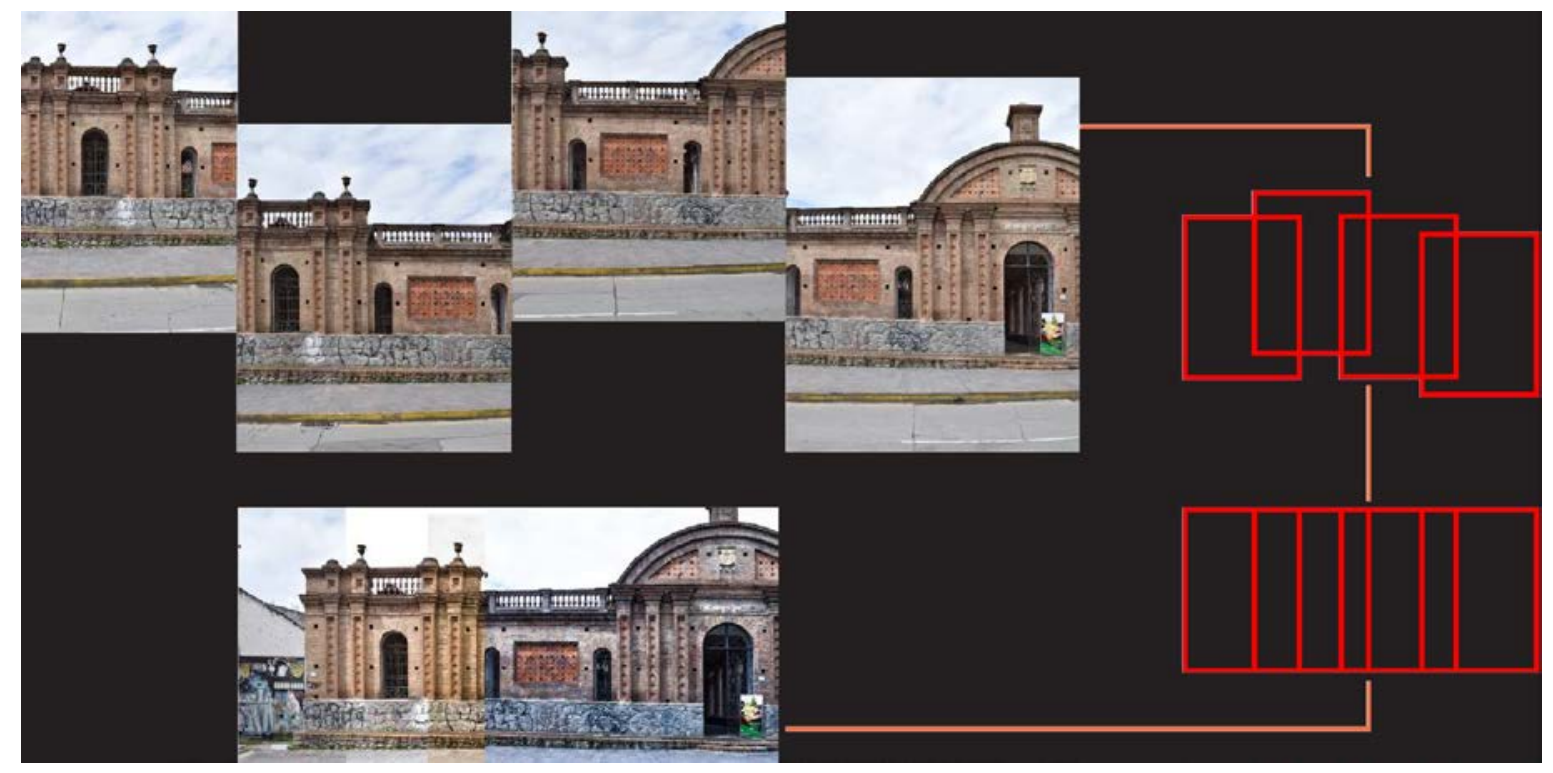

Figura 1. Traslape de fotografías.

El procedimiento para realizar el levantamiento de fachadas mediante el UAV difiere al del levantamiento ortogonal anteriormente explicado. El levantamiento de fachadas se realizó mediante el uso de la aplicación DJI GO², la cual deja de lado el vuelo automatizado de la aeronave para pasar a un tipo de vuelo manual. Es importante configurar la cámara con un ángulo entre $45^{\circ}$ y $80^{\circ}$ para asegurar que cada fotografía posea la mayor cantidad de información posible. 2 DJI GO: Es una aplicación que filma y comparte contenidos con la mayoría de los productos DJI, las series
Phantom 3, Inspire y Osmo. 
Debido a la complejidad del entorno de algunas edificaciones, como vegetación, altura, etc., fue necesario utilizar un escáner láser LIDAR, el cual ayudó a efectivizar la toma de información en los casos en donde las cámaras digitales y el dron no podían cumplir su objetivo. Estos levantamientos, se llevaron a cabo con la supervisión de un técnico especializado.

Los puntos base en donde se ubica el escáner LIDAR, antes de cada levantamiento, se denominan estaciones. Previo al escaneo de la edificación, es necesario identificar la posición adecuada desde donde se puede visualizar la mayor cantidad de información, esto con el fin de aminorar el uso de nuevas estaciones, y ubicar los diferentes objetivos esféricos y planares que facilitarán la referenciación de cada levantamiento en su posterior unión. Luego de un proceso de ensamblaje y nivelación del dispositivo, finalmente se establecieron los límites tanto verticales como horizontales $\left(150^{\circ}\right.$ en vertical y $360^{\circ}$ en horizontal) de la captura de información, así como la calidad y resolución, siendo éstas directamente proporcionales al tiempo de procesamiento de datos.

\subsection{Procesamiento de datos y visualización del modelo tridimensional unificado}

Al momento de realizar la documentación ortogonal del área de estudio y parcial de cada edificación, se tuvo como resultado un total de 2607 fotografías. Mediante el software Agisoft PhotoScan, se interpretaron las diferentes capturas fotográficas para luego representarlas como nubes densas de puntos, las que establecen la cualidad de tridimensionalidad. Este programa es una plataforma autónoma desarrollada por la empresa Agisoft y consigue los más altos estándares de calidad y precisión en las reconstrucciones realizadas (Agisoft LLC, 2016).

El primer resultado tridimensional visual que se obtiene con el proceso fotogramétrico del software, es la nube de puntos dispersa, la misma que, basada en un proceso de alineación de las fotografías e identificación de puntos comunes entre cada captura, generan un primer bosquejo en donde, gracias a la rapidez del proceso, se puede identificar tempranamente posibles errores o distorsiones presentes en el objeto levantado. En este procedimiento jugaron un papel muy importante los diferentes parámetros de configuración. La precisión es una de las variables más importantes, ya que mantiene una relación directa con el tiempo de ejecución. Precisión alta, media y baja, son las opciones que se pueden escoger en este apartado. Es importante mencionar que, para realizar pruebas piloto o prototipos rápidos se puede escoger un bajo nivel de precisión, sin embargo, al continuar con la siguiente etapa es necesario calidades altas.

La interfaz del software permite ejecutar una selección de puntos por emparejamiento, es decir, se puede identificar puntos coincidentes entre cada toma generada, con el fin de unificar y consolidar de mejor manera el modelo tridimensional. En esta sección existen tres modos de selección, el de referencia, en donde se ubicarán la mayor cantidad de puntos compartidos, consumiendo un mayor tiempo; el modo normal, en donde el proceso se realiza con un nivel inferior de precisión y calidad; y el desactivado.

Con el fin de disminuir la inversión de tiempo de procesamiento existen varias regulaciones. El límite de puntos por fotografía, indica el número máximo de puntos que encontrará el programa en cada una de las imágenes, en donde al utilizar el valor cero se ordena al software encontrar tantos puntos como sea posible, incrementando el tiempo y el porcentaje de puntos incorrectos generados. El límite de puntos de referencia, señala el valor superior de coincidencias entre los puntos de las fotografías. Como caso contrario al parámetro antes mencionado, al utilizar el valor de cero, se ordena al programa no realizar ningún filtrado ni revisión de cada una de las coincidencias, lo que provoca errores en la alineación final de las cámaras. Por último, es posible realizar una clasificación de puntos según las peculiaridades de cada uno, características como altura, color, entre otras, pueden ser mecanismos para excluir puntos del proceso posterior.

Previo a la generación de la segunda etapa de modelación, es necesario aplicar una depuración de la nube de puntos dispersa, ya que, a pesar de las configuraciones realizadas, existen varias distorsiones y puntos no deseados en la escena. Luego de obtener un modelo limpio, se prosigue con la generación de la nube densa. De igual manera, existen varias características que se puede estructurar según la finalidad. La calidad, al igual que la precisión en el proceso anterior, hace mención al tiempo que se invertirá para conseguir el objeto final. Los modos de filtrado son configuraciones que plantea el programa, con el fin de acoplar las cualidades del resultado a las características de nuestro entorno y la 
forma escogida de levantamiento. El modo de filtrado suave es útil cuando existen numerosos detalles importantes de pequeña escala que se desean distinguir espacialmente, lo cual es conveniente para la reconstrucción de los modelos parciales de fachada de cada edificación. En el modo de filtrado agresivo, se elude la identificación de objetos minúsculos y se enfatiza en el rescate de texturas amplias, siendo ésta la herramienta para modelar los datos del levantamiento ortogonal y finalmente el filtrado moderado, ya que tiene un nivel intermedio entre el suave y el agresivo, que facilita realizar pruebas al momento de escoger cuál de los dos modos es el factible para la reconstrucción tridimensional que se realiza.

Una vez que se obtuvieron las reconstrucciones de los levantamientos parciales de cada una de las edificaciones pertenecientes al área de estudio, se procedió a fusionarlos con la nube de puntos resultante del vuelo ortogonal. Para esto, se usó el software CloudCompare por su versatilidad y variedad de herramientas para el manejo y análisis de nubes de puntos. Mediante este software de licencia libre, se combinó cada una de las nubes de puntos parciales con la nube de puntos general, mediante un proceso de asociación, que se basa en pares de puntos equivalentes, el cual ensambla y escala los modelos tridimensionales (CloudCompare, 2015).

Una vez terminado el proceso de alineación de todas las nubes de puntos, estas mantienen su condición de ser archivos individuales, por esta razón fue necesario fusionar todos los archivos en uno solo, para así mejorar el rendimiento de los ordenadores y facilitar su manejo, migración y posterior visualización en otros programas.

Para la visualización del modelo tridimensional unificado del sector de estudio se exploraron varios tipos de software, de los cuales el que presentó mejor compatibilidad hacia los archivos de nubes de puntos fue Autodesk ReCapPro 2018. Este software, especializado en el procesamiento de datos LIDAR, posibilita la navegación, visualización y renderizado de la nube de puntos. Cabe destacar que para efectuar la importación del archivo dentro del software ReCap Pro 2018, este tiene que estar guardado en formato " $e 57$ ".

\subsection{Identificación de transformaciones urbano-morfológicas}

Al cabo de cuatro meses se realizó una nueva lectura de toda el área de estudio, con el fin de realizar un análisis comparativo e identificar posibles transformaciones que se hayan dado durante este tiempo. Para cumplir este objetivo, nuevamente fue necesaria la implementación del software CloudCompare, el cual ayuda a identificar y establecer numéricamente las variaciones entre levantamientos fotogramétricos de distintas fechas en una edificación.

Para este proceso, es necesario incorporar los dos levantamientos efectuados dentro de la interfaz del programa. Cabe mencionar que el formato admitido por la plataforma es LAZ ${ }^{3}$. Lo siguiente es la alineación de las dos nubes de puntos con el fin de geo-referenciarlas en el mismo lugar mediante el proceso descrito en la fase de procesamiento y visualización de los levantamientos reconstruidos. Posteriormente mediante la herramienta "Cálculo de distancias entre dos nubes de puntos", se procede a realizar el análisis con el que se identifican los puntos concordantes y los que presentan alguna alteración con respecto a la nube original, para luego generar los cálculos respectivos de las distancias absolutas entre ellos. El tiempo computacional para estos procesos depende directamente de las características que posea el ordenador. Luego del cálculo de distancias, los resultados se representan gráficamente, ya que, el modelo tridimensional comparado se grafica en una escala de color según la magnitud de las modificaciones o transformaciones suscitadas.

\footnotetext{
${ }^{3}$ LAZ: Es un formato de archivo para el intercambio de datos tridimensionales de nubes de puntos. Aunque se desarrolló principalmente para el intercambio de datos de nubes de puntos LIDAR, este formato admite el intercambio de datos tridimensionales de $\mathrm{x}, \mathrm{y}, \mathrm{z}$.
} 


\section{RESULTADOS Y DISCUSIÓN}

En la etapa de levantamiento de datos, existieron motivos por los cuales se utilizó una determinada herramienta y sus combinaciones. Los distintos tipos de implantación, junto con los diversos obstáculos y características de cada edificación, jugaron un papel determinante al momento de la elección de la herramienta. El dron Phantom 4 se utilizó para obtener datos de cubiertas y texturas en planta, mediante el vuelo ortogonal, además, en los casos de edificaciones de considerable altura, esta herramienta facilitó la captura de información en los lugares en donde otras herramientas presentaban desenfoque o distorsión debido a la distancia. Asimismo, ante la presencia de edificaciones que poseen muros no permeables en su cerramiento, la herramienta permitió sobrevolarlos y obtener la información necesaria. Frente a la limitación de realizar levantamientos de gran magnitud solamente con UAV y dos baterías disponibles, y debido al interés de probar la metodología con diversos tipos de cámaras, se incorporó el uso de una cámara semiprofesional Nikon D5300 de alta resolución (24 Mpx), una cámara GoPro Hero 3+ con lente gran angular, y, por la velocidad de captura de fotografías, una cámara común de un smartphone.

Para la generación de la nube de puntos dispersa, se trabajó con la siguiente estructura: precisión alta, selección de emparejamiento en modo referencia, límite de puntos por fotografía igual a cero, el cual se compensa con un número alto de puntos coincidentes de 80,000, con lo cual las posibilidades de error se redujeron significativamente. Con este proceso se obtuvo una nube dispersa (Fig. 2) con un total de 8'671,142 puntos, en aproximadamente 6 horas y 30 minutos de procesamiento del levantamiento ortogonal y 177 horas 26 minutos para las documentaciones parciales.

Para la generación de la nube de puntos densa ortogonal (Fig. 3) se usó un filtrado de profundidad agresivo, debido a que se trata de un levantamiento ortogonal hecho a 75 metros de altura. Las texturas y detalles pequeños no jugaron un papel importante en este caso. Al final se consiguió una nube de puntos unificada, en donde están fusionados los datos del levantamiento ortogonal y de fachadas, dando como resultado un total de 347'938.005 de puntos geo-referenciados.

Como se mencionó en la etapa de levantamiento, existieron algunas edificaciones que por las peculiaridades del entorno que les rodeaba, fue necesario documentarlas mediante un escaneo LIDAR. Estos inmuebles fueron el Centro Interamericano de Artesanías y Artes Populares (CIDAP) y la Casa Museo Remigio Crespo Toral. El levantamiento se llevó a cabo con altos porcentajes de calidad y resolución, el total de puntos entre ellas fue de 492’061.995 puntos. De esta manera, se concluye la etapa de generación de nubes de puntos de las fachadas (Fig. 4) para luego proceder a realizar el proceso de ensamblaje de la nube de puntos global.

El resultado del proceso de fusión de los levantamientos parciales con la nube de puntos resultante del vuelo ortogonal se puede observar en la Fig. 5.

La nube de puntos actual del sector del Barranco de Cuenca (Fig. 6) puede ser actualizada de manera periódica, mecanizando y acelerando los procesos de documentación patrimonial de la ciudad. Este recurso permite visualizar, de manera hiperrealista, cada uno de los detalles, sin obviar datos de estructura o textura. Debido a que se trata de un proceso fotogramétrico, basado en capturas fotográficas, permite generar un compendio de datos tanto tridimensionales como bidimensionales.

Adicionalmente, se realizó un estudio de los dispositivos de captura de información utilizados, con el fin de establecer su grado de versatilidad. Con cada uno de los instrumentos se efectuaron levantamientos de una misma edificación, para luego analizar los resultados en base a diversas variables. El tiempo de levantamiento hace mención a la duración necesaria para la captura de la información, esto permite identificar qué herramienta presenta una manejabilidad eficiente. El tiempo de procesamiento se determinó en base a la cantidad de fotografías realizadas y la calidad elegida para la reconstrucción, cabe mencionar que cada uno de los modelos fue probado en igualdad de condiciones (número de fotografías tomadas y ubicación de captura de imágenes) para que los diferentes resultados posibiliten visualizar las cualidades de cada artefacto. La calidad visual se encuentra directamente relacionada con la densidad de puntos encontrada en cada nube generada. Finalmente, se analizó el costo de adquisición de la herramienta empleada, con el fin de determinar cuál de ellas presenta mayor asequibilidad en nuestro medio. 


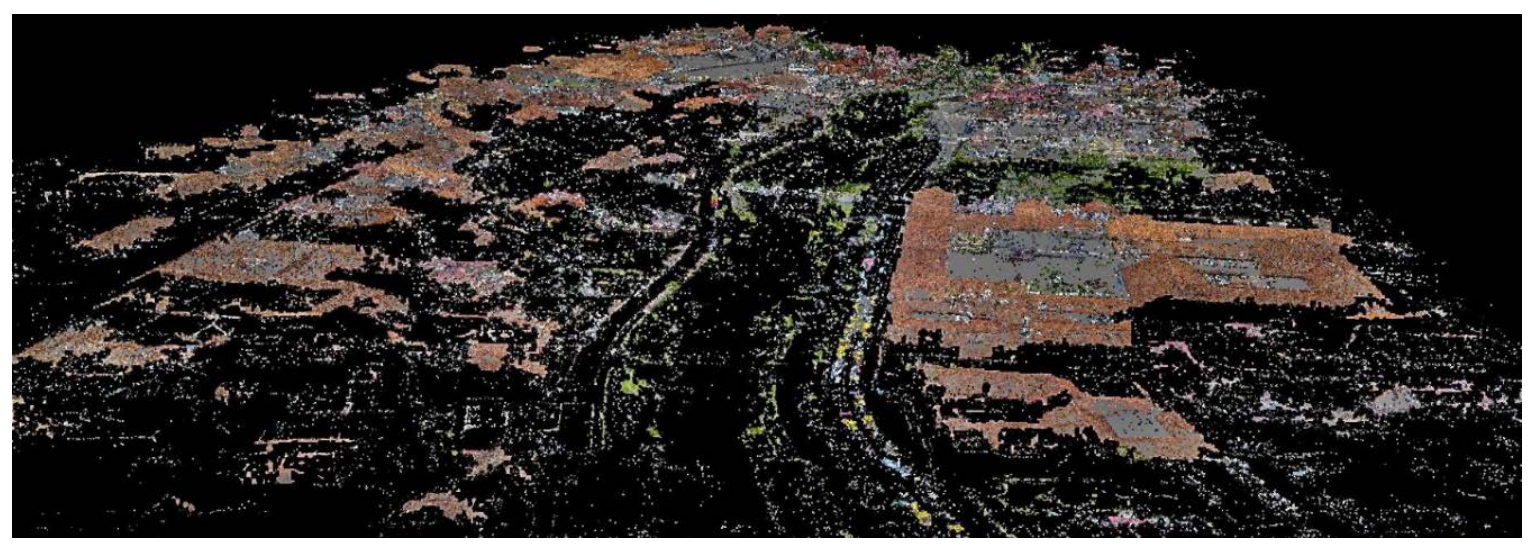

Figura 2. Nube de puntos dispersa.

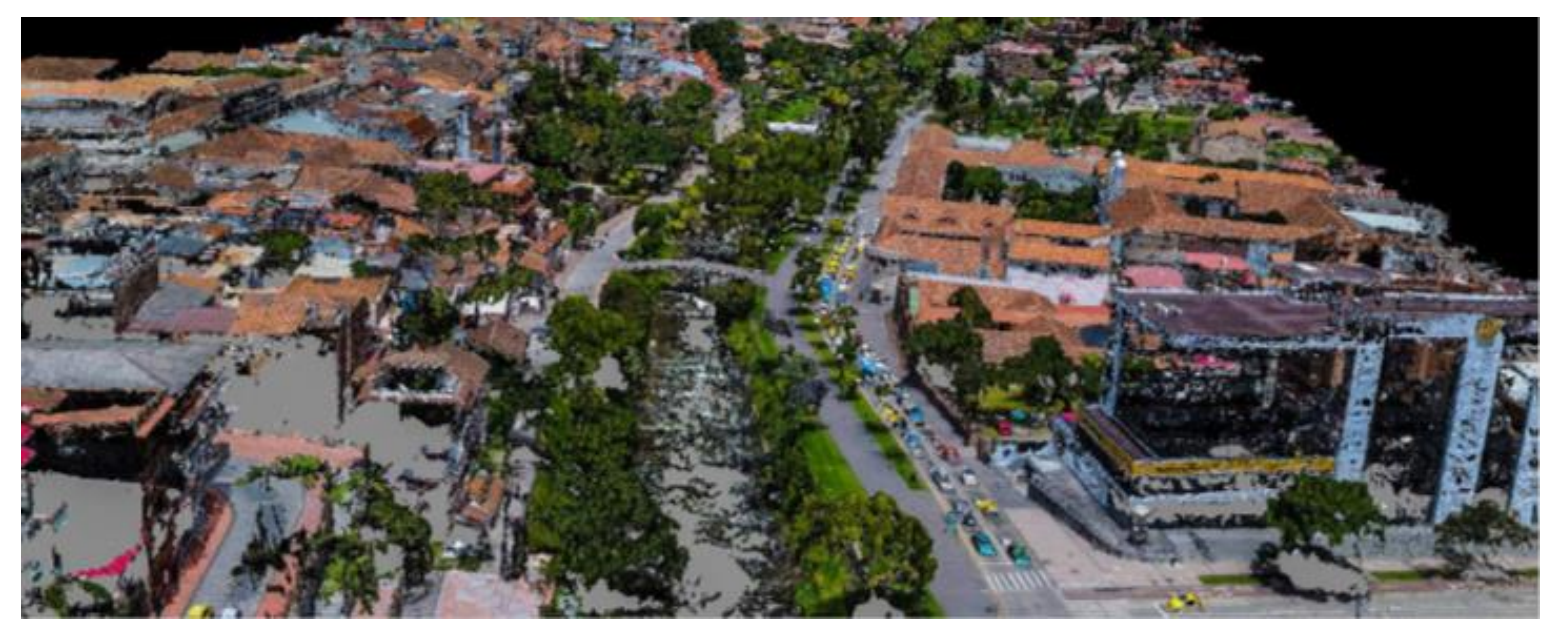

Figura 3. Nube de puntos densa

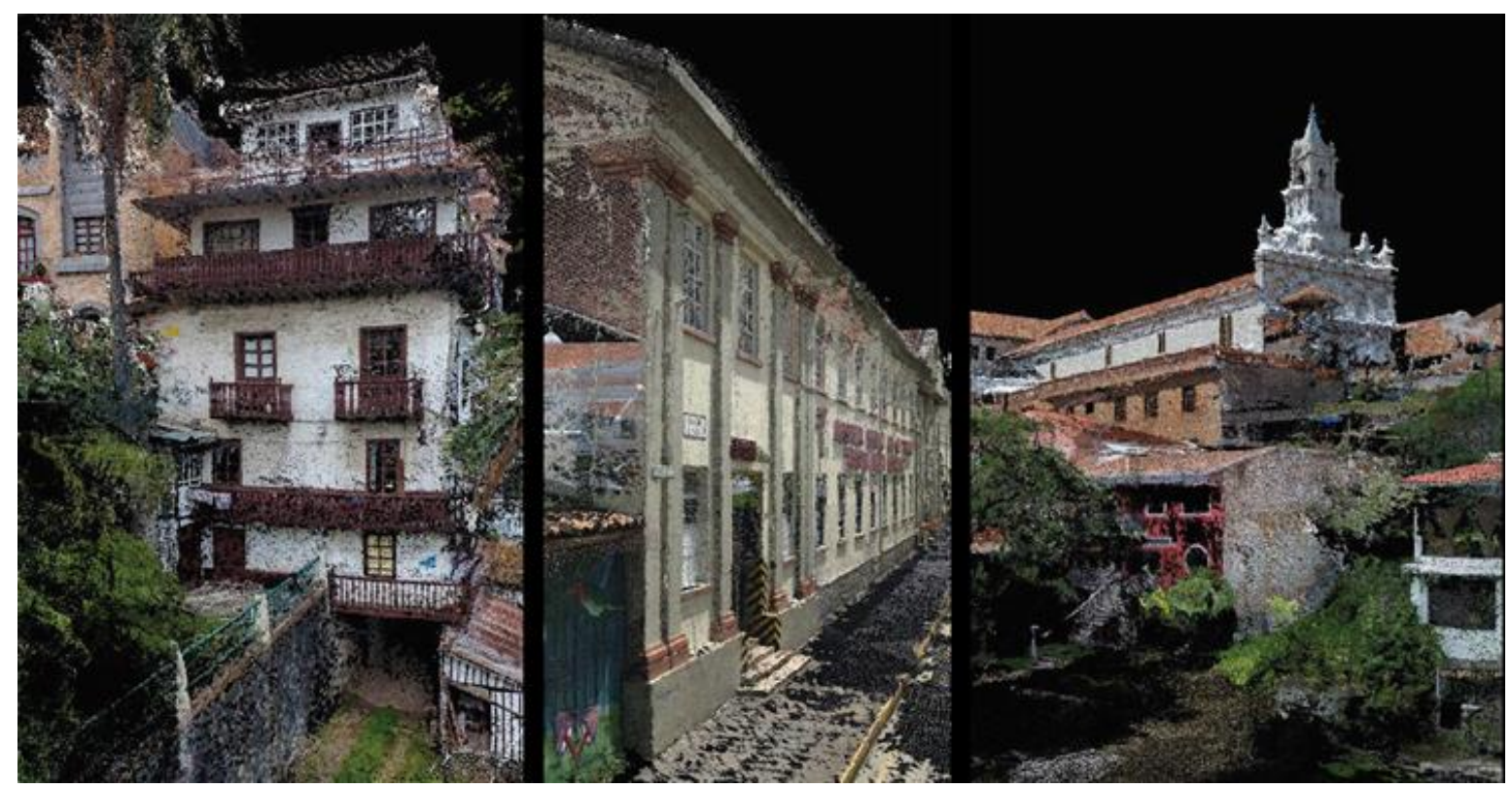

Figura 4. Reconstrucción tridimensional de fachadas 

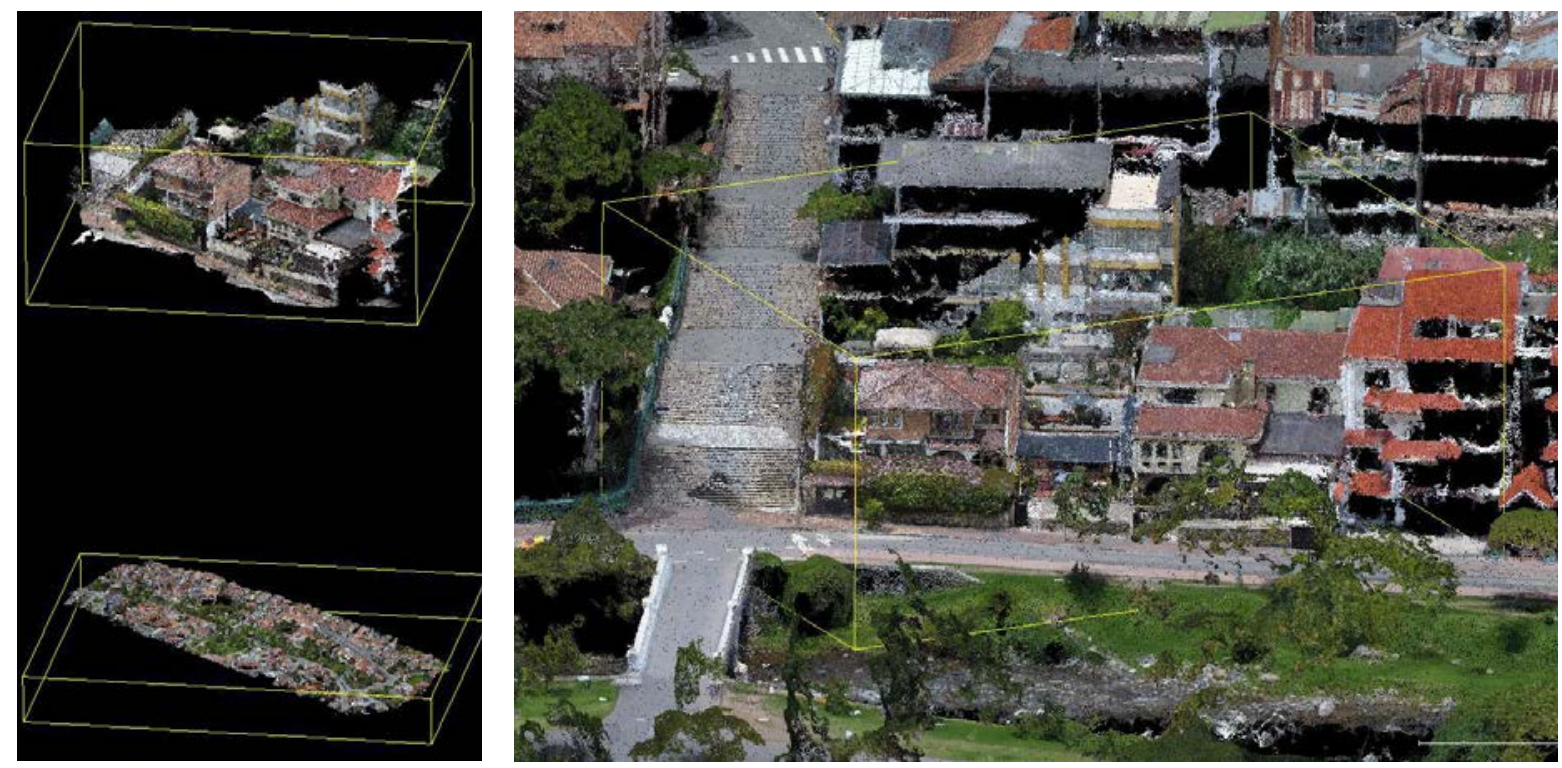

Figura 5. Alineación de nubes de puntos.

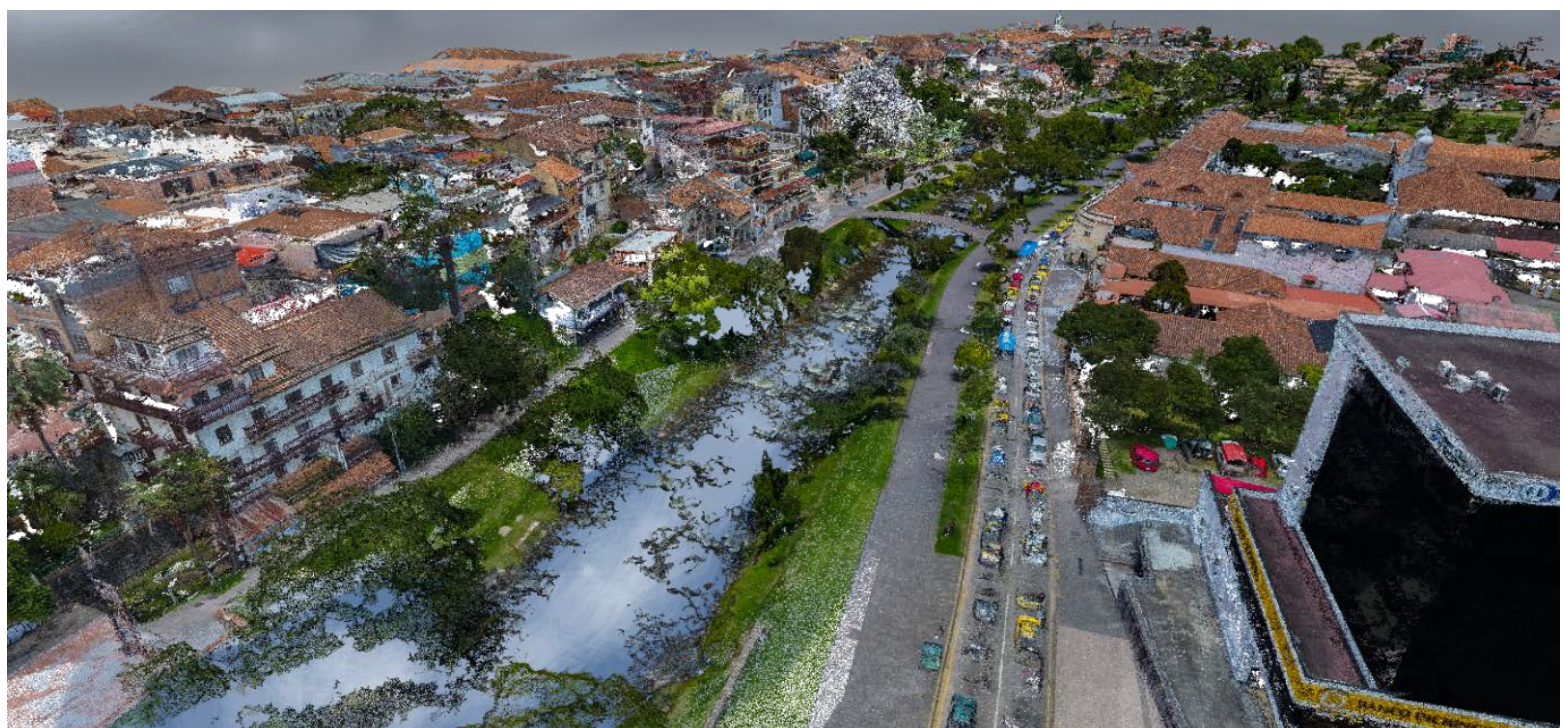

Figura 6. Perspectiva de nube de puntos densa de El Barranco en Cuenca.

Al momento de realizar el levantamiento con la cámara GoPro Hero 3, se pudo constatar la necesidad de efectuar combinaciones con otras herramientas para generar resultados óptimos, ya que los modelos conseguidos presentaron múltiples distorsiones en su representación visual. Por lo tanto, se realizó la misma reconstrucción utilizando fotografías capturadas con el dron Phantom 4, para compensar las distorsiones.

Dentro de las herramientas analizadas, que permiten la captura de información fotográfica o bidimensional, la que presenta mayor versatilidad es el UAV o dron, ya que su característica de tomar información a diferentes alturas permite la generación de modelos tridimensionales con mayor cantidad de datos y de mejor calidad (Tabla 1).

De igual manera, al confrontar los resultados obtenidos por el dron en relación con el escáner LIDAR, cabe resaltar que a pesar de que el vehículo aéreo provee más información por cada levantamiento, frente a la información terrestre de fachadas que provee el escáner, la calidad de la reconstrucción tridimensional generada por el escáner LIDAR es muy superior a cualquier otra obtenida, inclusive a la calidad resultante de la combinación de las cuatro herramientas fotográficas analizadas. 
Si bien la metodología analizada fue aplicada solamente en un sector específico de la ciudad, como es El Barranco, la complejidad que éste sector presenta (la presencia de edificaciones patrimoniales y contemporáneas con sus diferentes tipos de implantación, la existencia de vegetación alta, mediana y baja, el eje hidrográfico existente además de las riveras y microclima generado) deja abierta la posibilidad para que la metodología sea aplicada en un sinnúmero de contextos diferentes.

En conclusión, cuando se trabaja en un proyecto en donde se dispone de un presupuesto medio para el levantamiento (entre \$800 a \$2000 aproximadamente), de un tiempo limitado (una hora o menos) y las condiciones del contexto presenta vegetación de mediana y baja altura, la herramienta más eficiente que se puede utilizar es un UAV o un dron. En condiciones de presupuesto medio, con un tiempo de levantamiento medio ( 1 a 2 horas) y en un contexto en donde la edificación no presente obstáculos móviles o fijos a su alrededor, es ventajoso el uso de una cámara semiprofesional, debido a la alta calidad de fotografías que brinda. Cuando se dispone de un presupuesto bajo (menor a $\$ 800$ aproximadamente), escaso tiempo para el levantamiento y un contexto libre de obstáculos fijos o móviles, la mejor opción es el uso de un Smartphone, por su agilidad y velocidad para la captura de imágenes. Cuando se pretende tener más información con un menor número de fotografías, y contando con un presupuesto bajo, un tiempo de levantamiento medio y un contexto accesible sin obstáculos fijos o móviles, se puede utilizar la herramienta como la cámara GoPro, sin embargo, es importante tener presente que el uso de esta herramienta puede generar deformaciones en las reconstrucciones tridimensionales. Por último, si se dispone de un presupuesto alto, un tiempo de levantamiento alto y un contexto accesible, la mejor opción, debido a la calidad de las reconstrucciones tridimensionales, siempre será el escáner LIDAR (el costo de un escáner LIDAR bordea los \$75,000 en Ecuador) (Tabla 2).

Tabla 1. Cuadro comparativo de las distintas herramientas.

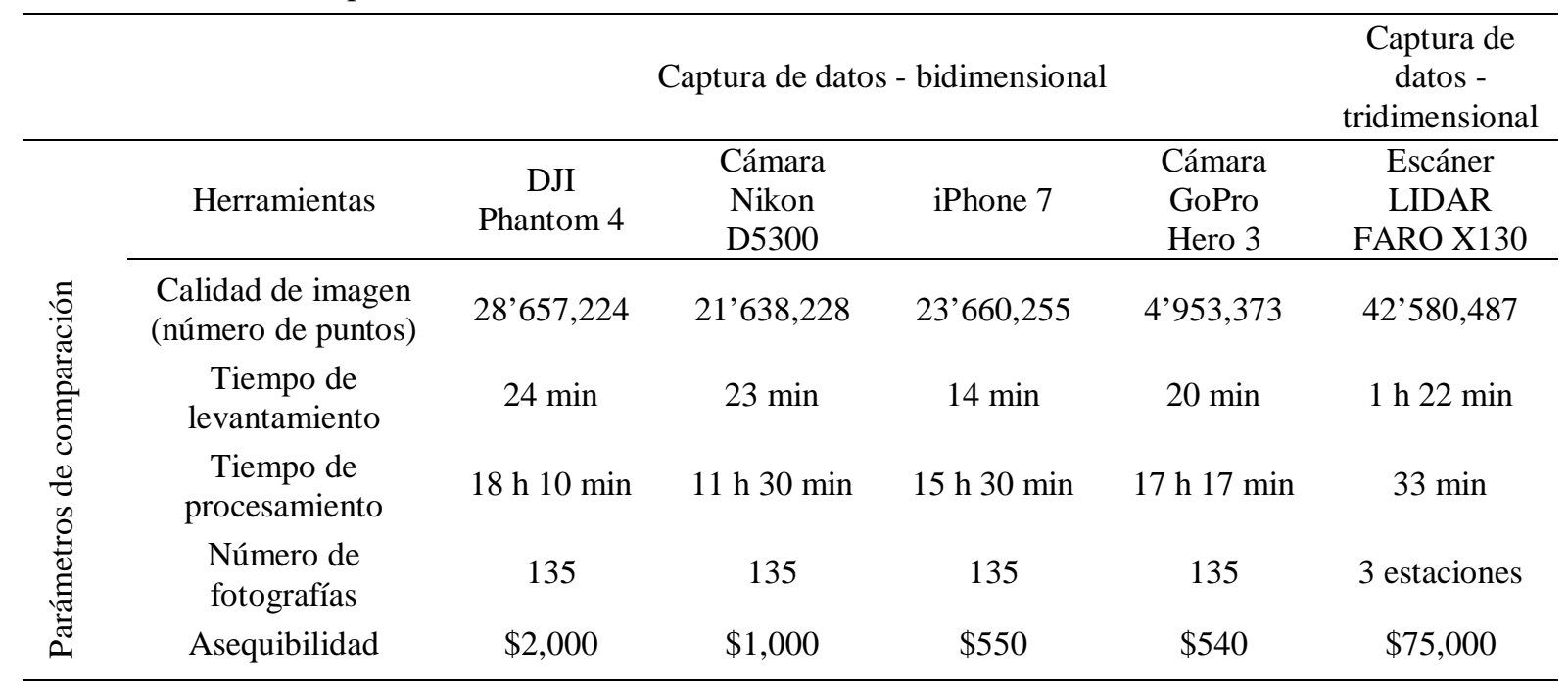

Tabla 2. Cuadro de rendimiento de herramientas.

\begin{tabular}{cccc}
\hline & Presupuesto & $\begin{array}{c}\text { Tiempo de } \\
\text { levantamiento }\end{array}$ & Lugar \\
\hline Dron Dji Phantom 4 & Medio & Escaso & Inaccesible (sin vegetación alta \\
o frondosa) \\
Camera Nikon D5300 & Medio & Medio & Accesible (sin obstáculos) \\
Smartphone Iphone 7 & Bajo & Escaso & Accesible (sin obstáculos) \\
Camara GoPro Hero 3+ & Bajo & Medio & Accesible (sin obstáculos) \\
Escaner Laser LIDAR & Alto & Abundante & Accesible (sin obstáculos) \\
\hline
\end{tabular}

Es de resaltar que si bien el uso individual de cada herramienta dejó resultados favorables, las mejores reconstrucciones tridimensionales mediante nubes de puntos, a través de un proceso fotogramétrico, resultaron de combinar las fotografías obtenidas por las cuatro herramientas utilizadas. 
Si bien no se pudieron combinar todas las herramientas para todas las edificaciones reconstruidas, buenos resultados se obtuvieron de la combinación del UAV o dron Phantom 4 con la Cámara Nikon D5300 y también de la combinación entre el Phantom 4 y el Smartphone Iphone 7.
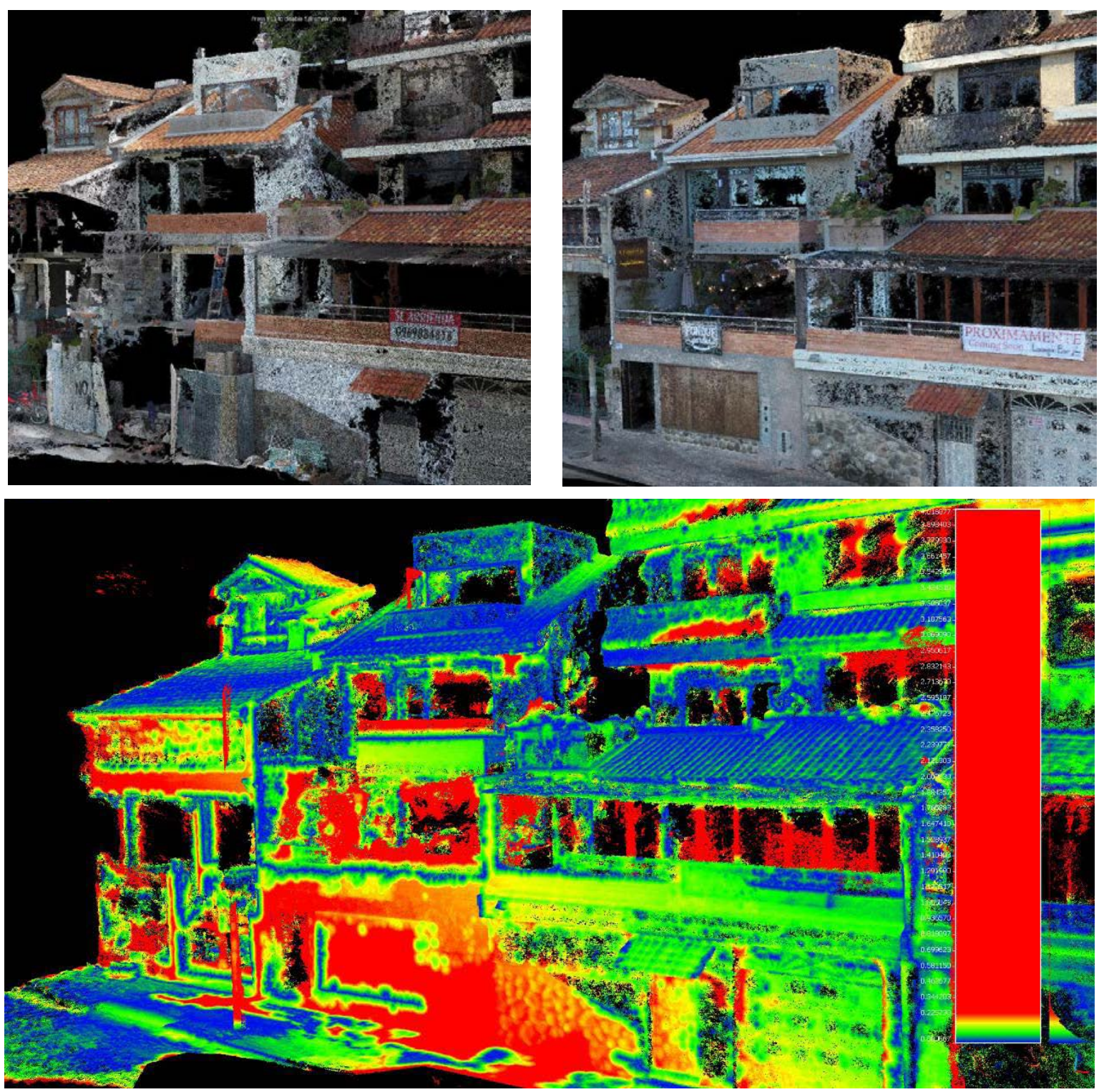

Figura 7. Análisis comparativo de nubes de puntos. Detección de una vivienda en construcción en la primera etapa y terminada en la segunda.

Los productos del análisis comparativo revelaron dos alteraciones en las edificaciones del Barranco en el período de estudio. Una de las edificaciones (Fig. 7), al momento de realizar la primera lectura, se encontraba en proceso de construcción, que finalizó durante la segunda documentación realizada; la otra (Fig. 8), fue demolida, el proceso brindó datos que corroboraron este suceso. Gracias al análisis comparativo entre nubes de puntos y los múltiples datos conseguidos en la etapa de levantamiento, se genera una compleja y actualizada base de datos documentada, tanto visual como mensurable que serán útiles para el estudio de sitios históricos e investigaciones sobre ciudad. Esta metodología resulta viable para una permanente gestión y control del patrimonio edificado.

En la investigación "Point Clouds as a Representative and Performative Format for Landscape Architecture” de Ervine (2016), se demostró que es posible elaborar una estrategia hipotética de mitigación de inundaciones a lo largo del río Cilliwung, Indonesia, mediante la captura, edición y manipulación de información en nube de puntos, al igual que el presente estudio, se concluye el 
proyecto utilizando los datos, herramientas y flujos de trabajo que se desarrollan conjuntamente con el avance tecnológico, en un entorno donde la problemática es real.
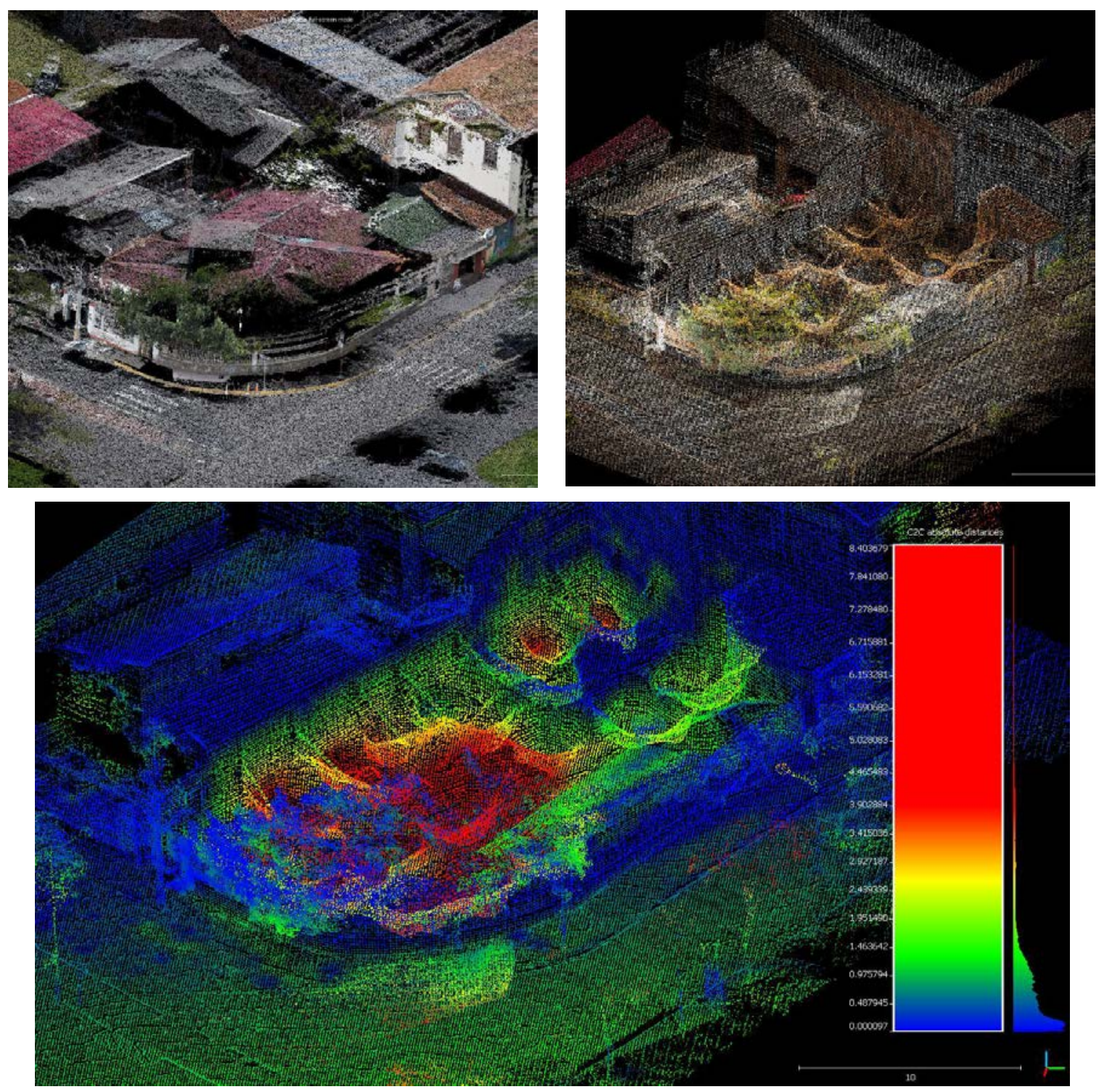

Figura 8. Análisis comparativo de nubes de puntos. Detección del derrocamiento de una vivienda.

Durante la etapa de levantamiento de datos (puntos) hubo diversas dificultades. Como se pudo evidenciar, una de las razones más frecuentes de la distorsión en la reconstrucción de los modelos tridimensionales es la presencia de objetos en movimiento como vehículos o personas, o estáticos como vegetación que interfieren en la escena. Debido a que los diferentes vuelos y capturas de información se los realizó en días despejados, la presencia de objetos con superficies reflejantes o transparentes como ventanas, causaron errores o pérdida de información. La dificultad de acceso a algunos predios dadas sus condiciones topográficas y de vegetación.

El uso de LIDAR o de las diferentes herramientas y combinaciones analizadas en el presente estudio, permite obtener datos mensurables de cualquier objeto escaneado, tal como el Puente Roto del Barranco de Cuenca. La adaptabilidad del proceso realizado en otros contextos, ya sean históricos o de otra índole, permite demarcar posibles estudios a futuro. Al igual que el caso del río Cilliwung en Jakarta (Ervine, 2016) (Fig. 9), la ciudad de Cuenca-Ecuador se encuentra interceptada por cuatro ejes hidrográficos, los cuales, en épocas pasadas, han sido protagonistas de panoramas catastróficos que podrían mitigarse aplicando este tipo de metodologías. 
Debido a los beneficios que se pueden lograr con una correcta restauración, conservación y mantenimiento de los bienes patrimoniales, es importante relacionar los lineamientos establecidos en cartas, ordenanzas y otros documentos, con la tecnología y metodología analizada en este trabajo.
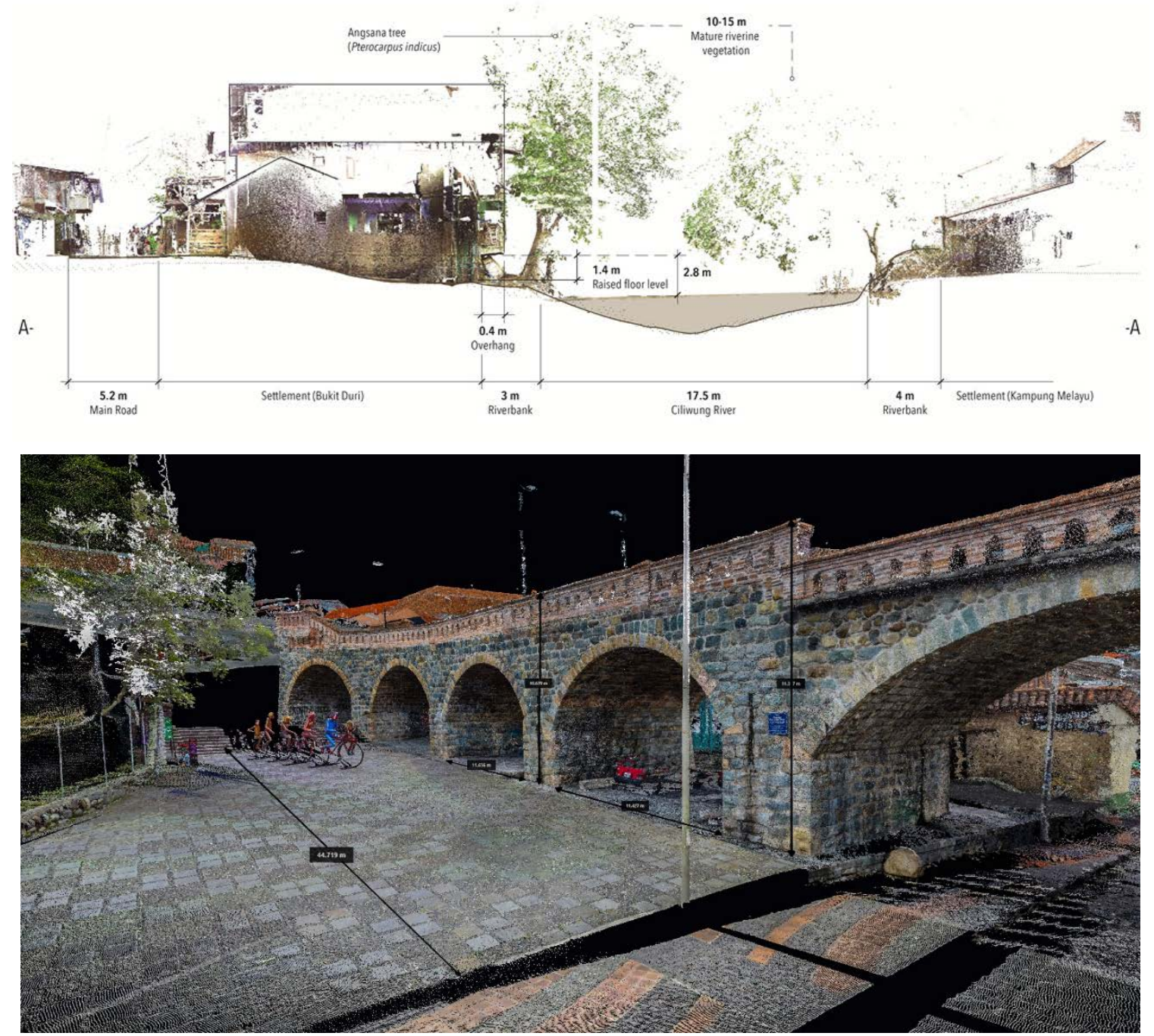

Figura 9. Modelos tridimensionales mensurables caso Jakarta (Ervine, 2016) y Puente Roto en Cuenca.

El Instituto de Patrimonio Cultural de España (2011) afirma que "la conservación preventiva representa fundamentalmente una estrategia basada en un método de trabajo sistemático, que tiene por objetivo evitar o minimizar el deterioro mediante el seguimiento y control de los riesgos, que afectan o pueden afectar a un bien cultural”, por esto, la reconstrucción tridimensional, mediante fotogrametría y escáner LIDAR, que permite identificar alteraciones y deterioros provocados por agentes naturales o por la población, resulta relevante. Dentro de los métodos de trabajo establecidos para esta investigación, se encuentra el diseño de métodos de seguimiento y control según los recursos disponibles. De este modo, en lo que a asequibilidad se refiere, los costos del proceso fotogramétrico son económicamente viables en comparación con la técnica LIDAR. En este caso, elegir la tecnología, el procedimiento y el flujo de trabajo adecuados, es siempre un desafío y depende del tamaño, complejidad y nivel de exactitud requerida (Grussenmeyer, Patias, \& Hanke, 2008). Cada tecnología tiene ventajas y desventajas. En la mayoría de los casos la combinación de tecnologías y metodologías puede ser la solución más beneficiosa (Guidi \& Russo, 2011; Grussenmeyer et al., 2008; Patias, 2006). 


\section{CONCLUSIONES}

Teniendo en cuenta que el patrimonio cultural aporta al fortalecimiento de la identidad de una sociedad, es importante guiar todos los esfuerzos posibles para su correcta prevención y conservación, finalidad que sólo se conseguirá con procesos correctos de gestión y control. Resulta interesante observar cómo los métodos de documentación han perdurado a lo largo del tiempo, levantando información que en la actualidad se vuelve obsoleta con facilidad, frente al avance tecnológico existente.

Este trabajo propone una metodología clara para documentación de edificaciones patrimoniales, y una evaluación de herramientas que servirá para estudios futuros, además se ha evaluado un amplio espectro de posibilidades para el control y gestión del patrimonio edificado. Las ventajas y desventajas de la metodología y de las herramientas analizadas, se determinaron durante el proceso de levantamiento y reconstrucción de los modelos tridimensionales, en donde aspectos como calidad de imagen, número de fotografías, asequibilidad y tiempo de levantamiento y procesamiento, determinaron su versatilidad. Otro aporte importante de esta investigación fue la amplia gama de plataformas virtuales y software usados para la generación de los modelos tridimensionales.

Tenemos claro que el patrimonio cultural edificado está sujeto a múltiples alteraciones producidas de manera natural (patologías) o por inserción de nuevos estilos arquitectónicos, los cuales muchas veces se ejecutan sin un correcto proceso de documentación y planificación. En este sentido, este trabajo sugiere herramientas para procesos de monitoreo y toma de decisiones.

Esta experiencia nos sugiere futuras líneas de trabajo como el estudio de alteraciones o intervenciones ilegales en la parte contemporánea de la ciudad de Cuenca; el estudio de patologías de bienes patrimoniales y no patrimoniales mediante el uso de un escáner LIDAR terrestre; la creación de bases de datos planimétricas de bienes inmuebles históricos mediante fotogrametría; y la identificación y análisis de construcciones y asentamientos irregulares.

\section{AGRADECIMIENTO}

Expresamos nuestros sinceros agradecimientos al grupo de investigación LlactaLAB-Ciudades Sustentables, del Departamento Interdisciplinario de Espacio y Población de la Universidad de Cuenca, por el apoyo incondicional para el desarrollo de esta investigación.

\section{BILBIOGRAFÍA}

Agisoft LLC. (2016). Agisoft PhotoScan user manual professional edition, Version 1.2, 103 pp. Disponible en http://www.agisoft.com/pdf/photoscan-pro_1_2_en.pdf

Bacigalupo, C., Cessari, L. (2003). Survey techniques and virtual reality for the recovery plan. The International Archives of the Photogrammetry, Remote Sensing and Spatial Information Sciences, XXXIV(Part 5/W12), 40-42.

Borrero Vega, A. L. (2006). Cambios históricos en el paisaje de Cuenca, Siglos XIX-XX. Procesos Revista Ecuatoriana de Historia, 24(II Semestre, 2006), 107-134.

Cámara, L., Latorre, P. (2003). El modelo analítico tridimensional obtenido por fotogrametría. Descomposición, manipulación y aplicaciones en el campo de la restauración arquitectónica. Arqueología de la Arquitectura, 2, 87-96.

CloudCompare. (2015). CloudCompare, Version 2.6.1. User manual. Disponible en http://www.cloudcompare.org/doc/qCC/CloudCompare\%20v2.6.1\%20-

\%20User\%20manual.pdf, 181 pp. 
Doherty, M., Nakanishi, H., Bai, X., Meyers, J. (2009). Relationships between form, morphology, density and energy. GEA Background Paper, 1-28. Disponible en http://www.iiasa.ac.at/web/ home/research/Flagship-Projects/Global-Energy-Assessment/GEA_Energy_Density_ Working_Paper_031009.pdf

El-Hakim, S., Whiting, E., Gonzo, L., Girardi, S. (2005). 3D Reconstruction of complex architectures from multiple data. ISPRS Int. Workshop on 3D Virtual Reconstruction and Visualization of Complex Architectures (3D-Arch'2005), Venice-Mestre, Italy, 9 pp.

Ervine, L. S. (2016). Point clouds as a representative and performative format for landscape architecture. A case study of the Ciliwung River in Jakarta, Indonesia. Dissertation doctoral, ETH-Zürich, Suisa, Nr. 23299, 184 pp. https://doi.org/10.3929/ethz-a-010638407

Grussenmeyer, P., Patias, P., Hanke, K. (2008). Applications in cultural heritage documentation. In: ISPRS Congress Book, Baltsavias, E., Li, Z., \& Chen, J. (Eds.). CRC Press, pp. 363-383, https://doi.org/10.1201/9780203888445.ch27

Guerrero, J., Pajares, G., Guijarro, M. (2011). Técnicas de procesamiento de imágenes Estereoscópicas, 21 pp. Departamento de Ingeniería del Software e Inteligencia Artificial, Universidad Complutense de Madrid. Disponible en https://www.researchgate.net/ publication/47640074p

Guidi, G., Russo, M., (2011). Diachronic 3D reconstruction for lost cultural heritage. International Archives of the Photogrammetry, Remote Sensing and Spatial Information Sciences, XXXVII(5/W16), 371-376.

Jáuregui, L. (2001). Fotogrametría básica. Disponible en https://www.scribd.com/document/ 300706892/Fotogrametria-Basica-Luis-Jauregui, 171 pp.

Patias, P. (2006). Cultural heritage documentation. International Summer School: Digital Recording and 3D Modeling. Aghios Nikolaos, Crete, Greece. 21 pp. Disponible en https://pdfs.semanticscholar.org/cddb/9d9dec8d69cc25668f01c7d2c0f910220477.pdf

Perera, S. (2015). La ciudad entendida como un organismo vivo. Madrid, España: Universidad Francisco de Vitoria, 51 pp. Disponible en http://ddfv.ufv.es/bitstream/handle/10641/ 1148/SERGIO_PERERA_CONCEPCION_ENSAYO.pdf?sequence $=1$

Querol, M. Á. (2010). Manual de gestión del patrimonio cultural. Madrid, España: AKAL, 544 pp.

Remondino, F., Barazzetti, L., Nex, F., Scaioni, M., Sarazzi, D. (2011). UAV photogrammetry for mapping and 3D modeling - Current status and future perspectives. International Archives of Photogrammetry, Remote Sensing and Spatial Information Sciences, XXXVIII-1(C22), 25-31.

Samper, P. G. (2003). El sentido urbano del espacio público. Bitácora, 1(7), 13-18.

Vidanovski, M. (2016). Autodesk Community. ReCap Forum. Disponible en https://forums.autodesk.com/t5/ realitycomputing/what-makes-photos-good-forphotogrammetry-how-to-take-the-best/ba-p/5738392 